\title{
The Promise and the Lie of Humanities
}

\author{
Mohamed Shafeeq Karinkurayil \\ Post Doctoral Fellow, Manipal Centre for Philosophy and Humanities (MCPH), Manipal \\ University, Karnataka. Orcid Id: oooo-0oo2-8163-0594. shafeeq.vly@gmail.com
}

Received May 20, 2017; Revised July 02, 2017; Accepted July 10, 2017; Published August 10, 2017.

\begin{abstract}
The rising regime of technocracy has generated a slew of self-appraisal on the role of Humanities in the contemporary world, and especially in the institutional location of University. The location of the university is not placed absolutely within the premises of learning but has from the colonial times imbricated itself with the question of social and economic mobility. The university in the postcolonial India continues to be a site of allocation of resources and as such is overdetermined by questions other than the purely academic. This paper delineates the twin concerns for Humanities in India and argues for Humanities which will creatively amalgamate the two concerns that have been worrying it in India - that of the rise of technocracy, and that of a non-complementarity between learner aspirations and institutional requirements. Towards this, the paper advocates on stressing the mutuality of the experience of modernity, thus stressing simultaneity over historicity.
\end{abstract}

Keywords: Humanities, technocracy, India, Sarukkai

\section{Introduction}

Reports abound that soon a vast majority of jobs presently undertaken by human beings will be taken over by robots. Some of them also urge the working class to then channelize their anger appropriately - against the increasing mechanization of jobs as against the alleged migrants who are stealing these jobs away from them. A random search for "your job will be taken" on youtube throws up dozens of videos, from TED talk to reports from big media houses to sundry discussions, all of which focus on the role of automation in the contemporary work scenario and how it alters criteria of future employability. From BBC's Click to Garry Kasparov (2017), the salience and peculiarities of human and artificial intelligence and their interface have moved away from the academic to an everyday concern. The increasing mechanization of routine affairs, combined with the anger of the lower classes against an intellectual elite who has alienated themselves from those for whom they purportedly speak, the rhetoric of going back to real life and real people often issued by rabble rousing politicians, the perception that the future jobs in a mechanized future will necessarily have to be about supervising these machines, the bleak scenario attendant of every financial recession, the mantra that one has to make it quick and young - all these are part of what is generally perceived to be what ails the Humanities today globally. In the present piece I will be looking more closely at the Indian situation, and I will be arguing that it is from within the environs of crisis that the Humanities will have to rediscover itself.

(C) AesthetixMS 2016. This Open Access article is published under a Creative Commons Attribution Non-Commercial 4.0 International License (http://creativecommons.org/licenses/by-nc/4.0/), which permits non-commercial re-use, distribution, and reproduction in any medium, provided the original work is properly cited. For citation use the DOI. For commercial re-use, please contact editor@rupkatha.com. 
The ascendant technocracy of the world, even as it has destabilized the conventional mode of Humanities of long and engaged tenure of study, has thrown up a different scenario which Humanities cannot wish away. Added to this is the fact that Humanities is also the first in line at the receiving end in institutional measures of austerity. Combine this with general apathy towards what is perceived as a bunchy of dreamy kids speaking high sounding words and dropping names and terms, it looks like we are set for perfect doom. However, the very technocracy with its regime of simulation and mass transfer of goods, people, and ideas, might prove to be a robust occasion for the discovery of the aggregation which finds its lineage from the ancient discipline of rhetoric. My concern in this paper is to argue for Humanities which will creatively amalgamate the two concerns that have been worrying it in India - that of the rise of technocracy, and that of a non-complementarity between learner aspirations and institutional requirements.

\section{The Lie of the Humanities}

One of the momentous statements in reading literature in the age of digitalization has been from Franco Moretti who has called his practice of 'distant reading', "a little pact with the devil" (Moretti 2000, 57). The professed idea of distant reading, advocated by Moretti, is to jettison close reading of select (high) works in favour of bulk scanning practices involving technology such that wide themes, genres etc. can be mapped across a vast amount of literature over a large gap of time. While 'distant reading', as Moretti calls this practice, is more of a methodological turn in the study of literature, pedagogical tools have been transformed to keep tuned to the technocratic realities of the present day in a more sustained manner. The bonus of using multimedia classrooms and techniques in assessing API scores is an example of this. On the other hand, several new techniques of research have opened up or have been optimized in the study and concerns of humanities with the newer technological possibilities. An example of this is how big data has found use in researching the everyday, much like a realization in another dimension of Certeau's "Walking in the City" (1984). Technological advances have also lend its force to studies on environment and interdependent existence of human beings (Bennett 2010).

The question of the future of the institution of university, and especially that of Humanities therein have raised heat in India too in the recent years. In a recent conference on "Human Sciences and the Future of the University" held in the University of Hyderabad, the papers presented belonged broadly to be addressing two different concerns, one of digitalization or technocracy and attendant worries, and the other about the failure of the university as an institutional mechanism to deal with the newer segments of population which have found universities accessible only now (see also Tharu 2016). While the earlier concerns itself with questions of funding and disciplinary relevance, the latter responds to the recent student suicides. Both of these concerns find it necessary to call for a revision of pedagogic practices if Humanities, and University itself, is to stay relevant in the future.

One of the immediate trigger for the present piece is Sundar Sarukkai's recent paper titled "Location of the Humanities" (2017) where the author elucidates the different crises that hovers over this aggregation of disciplines called "Humanities" in India. Sarukkai begins with the first set of concerns, that of funding and institutionalization of University and Humanities, to proceed to a deeper understanding of what Humanities means in a cultural milieu as is obtainable in India. Sarukkai identifies the different issues that seem to ail Humanities - the untranslatability of Humanities into a world view which is conditioned by the sciences and the management according to which 'knowledge' should be 'useful', the institutional sidelining of Humanities in 
terms of allocation of resources which is a by-product of the same worldview, the public perception of Humanities as an avenue of gap filling or welfare (like when girls are waiting to get married), etc. However, Sarukkai continues, a deeper malaise ails Humanities in India, and this is the question of location. That Humanities was forged in the West is commonplace. But that the West also continues to channelize the psychic life of Humanities is a matter of concern. Sarukkai gives the example of the idea of 'crisis' itself - the crisis is in fact originally a result of the organic circumspection on the position of Humanities in the face of the second world war, which we in India do not share. Beginning from here, Sarukkai goes on to the need for relocating the Humanities in the Indian context. One is then confronted with many other problems here, that Humanities is not exclusive to universities is not the least of them.

Sarukkai proceeds to map out the alienations that are at play in Humanities in a location like India. Crucial among these is the inability of the university to make sense of the lifeworld of the Indian public. Humanities in India is practiced at the formal and the informal levels in India. While universities and colleges belong to the former, the family, the religious institutions and public intellectuals - institutions which offer discourse not just on religion or philosophy but also ethics and aesthetics as well - form the latter. In India one can acquire philosophy in a sermon in the football ground or a mutt. One is schooled in Humanities in the family. These trainings stand at a remove from the Humanities taught in the Universities for the very language - the terms and concepts that define and produce the concerns of Humanities - is alien to these myriad ways of living in Humanities. This is the primary question of location that Humanities must confront in India.

Sarukkai's prescription to the question of 'usefulness' is a strategic shift to 'applicability', such that the insights of Humanities, like Mathematics, can find application in a range of other fields. This is a robust suggestion and our institutions need to dedicate concerted effort as to how to hone this applicability, and also render clear the ethical impulse behind this.

Sarukkai concludes his essay by asking us to deliberate on the location of Humanities in India what it is and what it should be, if there is a possibility of 'global Humanities' and if so, what should be its method. But more importantly for him, we should ask ourselves what the catalyst of Humanities should be in India (Sarukkai 2016). Sarukkai's highlighted answer, surely one among the possible, is to present Humanities "as a bulwark against scientific and technological modernity" (161). Before one jumps on the author for what would seem like a claim for a return to an indigenous past, Sarukkai gestures to the possible resource for this resistance from France and German thought as well (Sarukkai 2016).

Sarukkai's is one voice among many who sees a different role for Humanities in the new era of technocracy. The role of Humanities is now found to be a part of the complex process of modern living with its structures of governance. Humanities is now found to be useful in professional services which involve emotional intelligence, such as in the field of medicine (Huat, 2016).

It is almost a cliché to say that what Humanities offers is a critical consciousness. Let us begin with a small application of it, never mind the cliché. 'Knowledge' is produced everywhere, in mutts, in dars, and at the dining table. Why privilege university at all? The university is a centre of production of a particular knowledge - where certificates essentially work as bonds which can be encashed later and globally so - a traveller's cheque verified by transcripts, conference presentations, journal publications, API scores and whatnot. What one desires is not just that Humanities should be true to its locations but that this organic Humanities should also be validated in the Other's eyes. What might then in fact save Humanities in India would be to stay true to this actually existing globality of education, and account of our contemporary selves, our 
torn, tattered selves which struggle to come to terms with their own being - our actual as opposed to ideal location.

What Sarukkai misses out, and is so conspicuous, is that modernity-globality as it presents itself in India as an amalgamation of Western and indigenous thought, mass movement of people across vast geographies and cultural landscapes, governmental technologies of surveillance and welfare, and the struggles for universal dignity of humankind, all of which intersect in our university spaces, might indeed be the catalyst that could drive forward towards a Humanities that is at once 'national' as well as global, precisely because these national conditions find their counterparts in other national situations by the sheer fact of living under global capitalism.

\section{....and its promise}

In her magisterial study of the introduction of English in India, Masks of Conquest (1989), Gauri Viswanathan refers to a peculiar condition which arose as a result of colonial education which she calls 'The Failure of English'. To put it briefly, and somewhat simplistically, the failure that Viswanathan refers to here is the unintended causality of English learning among Indian subjects which linked this western education with the promise of landing a job in the colonial machinery and consequent social mobility. While in England the hegemony of class played out such that education could be contained as inconsequential to the class relationships, the English education in India was caught up with aspirations of social mobility, a fact that was not well received by the colonial masters. Western education in India tinkered with social relations such that it created a class of 'mimic men' who sought a place between the natives and the Masters (Bhabha 1984) and who also sought to establish themselves as a caste through differential practices (Prasad 2014). The question that confronts us today, which often gets enunciated as "the crisis in Humanities" has also partly to do with this old colonial question - that if Humanities can be and should be saved from this link between education and upward mobility.

The link of education to social mobility and mobilization is arguably the most momentous force of change in contemporary India. The failure of (the) English to quell aspiration continues to be the democratizing promise of education in India. The Mandal agitation, which sought for representation of the depressed classes of India in jobs and public universities, did not just change the face and demographics of the universities, but also through its stages of revolution and counter revolution split Indian history into pre and post Mandal-Masjid. This period is decisive in the way the questions of caste, and secularism became central to electoral mobilizations. The period also brought into play the idea of "youth" as well as "aspirations", which would later refashion popular culture in crucial ways. The twin concerns of universities can both be traced to the early nineties, with the historic Liberalization-Privatisation-Globalization on the one hand, and the fights for reservations and anti-reservation agitations on the other. While LPG loosened the regulatory arms of the government and set the stage for aspirations of the lower classes (Menon and Nigam 2007), the Ramjanmabhoomi agitations, a counter to the caste battles, brought the various nodes of the nation into spatial network of affect (Deshpande 1995). Entry to universities was not just a matter of pursuing knowledge, but also of demanding that the Republic fulfilled its egalitarian promise. The last one and a half decade has been characterized by a churning in the field of higher education in India, where students from the 'hinterlands' of cultural landscape has claimed for themselves the promise of January 26 , which is to move away from subjecthood to taking charge of one's lives as citizens (Tharu et al. 2007). 
The question one should then worry about more than the supposed 'intention' of the participants in a Humanities programme is if Humanities is able to cater to the aspirations of these new faces who are first generation entrants to the University space and who for whatever reasons land themselves in a Humanities classroom. Do we have a Humanities that will cater to their needs, or at least elicit sufficient interest even as they are in transit? Do we speak to the reality of their everyday lives spent between the classrooms and their crowded hostels? As long as one does not write off the many convulsions in our university spaces as 'dirty politics' one realizes that the potential of university is not that of pure knowledge or deliberation, but the sublimation, the change of significations one is forced into in this face to face with the Other who cannot be subsumed anymore in the tired metaphors of 'family'. One then cowers, shuts oneself off from this discomfort, or one faces this otherness in a spirit of reevaluation. Fortunately for us, the University is not a family or a mutt - it is a public institution where the certainties of home will have to be deliberated upon self reflexively, and, if need be, drained down too. The organic crisis that Humanities in India has to confront and gain from is this very fact of university being a meeting place, a place of alienation rather than being at home. What one could wish for is for it to be alienating for all and not for some.

Humanities in India, if it is to fight redundancy, is ill-served by substituting 'western' with 'Indian' (from 'Language in Western Thought' to 'Language in Indian Thought'). One is reminded of Ramanujan's essay “Three Hundred Ramayanas: Five examples” which caught all the wrong attention while the central concern of the essay was conveyed in the second half of the title, "and three thoughts on translation". Rather than seek 'Indian' (which for many in academia only means Sanskrit) theories of translation, Ramanujan quietly and unceremoniously shows the door to the cardinal principle of translation in Western thought, namely, the primacy of the written word (Ramanujan 1991). This is the kind of paradigm shift one hopes for and is denied when Indian Humanities think routes to provincialize Europe by reproducing their own Europes. Humanities in India would be better served if it severs its obsessions with 'being true to the self and rather deliver to the simultaneity of lifeworlds that populate our universities.

Even the question of the demographics of the classroom, is not peculiar to India, and is as relevant in, say the US, as it is here. Spivak, for example, discusses the question of how to teach Humanities in a culturally non-homogenous classroom and argues for cross-cultural understanding based on shared experiences. Students from as varied location as Male and Japan can thus share, though tangently, experiences of occupation by foreign forces (Spivak 2012). One could compare this to, say a course on migration in an Indian university, with, typically, students from as far flung regions as each other as from the North East India to Kerala to Rajasthan to Delhi. Migrations are not a foreign affair for any of these students and they themselves are part of that huge flow of rural to urban migrations. The material for such a course is broad in its regions of interest - the migrations from North Eastern India to the Indian mainland, the migration of low skilled labourers from Kerala to the Arabian Gulf, of the internal migration from rural to urban China, and of the Turkish migration to Germany. The readings could be a mix of short stories, novels, and also sociological and anthropological studies. One of the objectives of this course, if one is to incorporate these many different faces to a point of convergence, would be to participate in an attempt at reading literature which would replace the schema of rootedness with movement and simultaneity - a world literature named so for the way in which the global movement of goods, capital, ideas and people constitute its condition of possibility. Humanities, in such a context, will have to relinquish its hootings for rootedness and instead argue for simultaneity, such that one could see, in the juxtaposition and commingling of genres a condition that would/should ideally characterize modernity - that of cosmopolitanism (Boes 2012). 
Cosmopolitanism in the Humanities classroom thus becomes a process of interrogation of shared routes between selves. Where does one map the belonging of all of us, torn as it is between languages Indian and English, being children to parents and citizens of the country? Where should we begin to chart our philosophy - in Arabic, Latin, Sanskrit, in the folktales of the twelve children born out of the Pariah woman, or in our entangled family lores? ? $^{\mathrm{i}}$ If we are looking for commonality, should we locate the bare minimum or the highest denomination of commonality (both of which will be that we all speak English)? One of the 'achievements' of the course was to experiment with a mode of reading that will take literature out of its Romanticist moorings of attachment to, as Herder would have it, "...its history, out of the spirit of the age, manners, opinions, language, national prejudices, traditions, and pastimes, even out of carnival plays and puppet plays" (Herder 2008, 25), and instead to engage in "a new critical grammar" (Adelson 2005) which would place literature in the here and now of localities constituted through landscape and possibilities and hindrances created thereby, but also through governmental measures, technologies of communication, and in and out migrations (Appadurai 1996) that lend these localities something of spontaneity and dynamic diectics.

\section{Conclusion: Hospitality as a Pedagogic Practice}

At the turn of the last century, in his deliberations on the concept of global city, Jacques Derrida spoke of the role of hospitality in the making of such cities (Derrida 2000). In the formulation of this concept Derrida borrows heavily from Emmanuel Levinas, who in his Totality and Infinity (1969) conceived of an ethics which is based on the face-to-face with the Other. The Other in Levinasian terms is a complete stranger who cannot be incorporated into the categories one is familiar with, and is therefore an excess. The ethics of face-to-face as one is faced by a stranger is activated by the sense of responsibility, in which the host feels responsible for the guest who has chosen the former to be the host. This is a reversal of the ethics of the Kantian cosmopolitanism in which the laws of the land are paramount. Derrida's deliberation was in the context of the refugees and the asylees who were knocking at the doors of Europe then. The situation had only gotten aggravated thence.

The reign of technologically mediated lives and the increased flow of populations, capital, and ideas across the globe has brought the scenario of global city a living reality in classrooms, and not only in India. On the one hand the cyberspace has allowed us to be anonymous or assume pseudo identities (Wood and Smith 2005) and on the other, it has loosened the link between the body and identity (Shapiro 2015), allowing for complimentary and contradictory presencing in different spheres of existence including different Multi-User Dungeons (MUD). While the students of a classroom cannot have been at any point of time reduced to their role as students, the cyberspace has allowed for a proliferation of these social profiles not just as alterations in workplace registers (such as a student might also be a farmer) but also has augmented the possibility of mutually isolated spaces of existence. On the other hand, the arrival of the new entrants to the university space in India has brought forth the reality of the pedagogic materials being impoverished to meet the aspirations of the new folk. In a rehash of the old postcolonial rebellion against colonial literature, the arrival of new entrants have forced disciplines to recenter the question of power towards the faultlines of everyday existence rather than map them out in macro terms of colonialism and nationalism (Prasad 1996). The university as an institution with all that it includes - the traditions of learning and teaching, the capacities of the personnel, as well as the mechanisms of mundane administration - is now faced with an Other which cannot be subsumed under the already known and therefore has to open up to the possibilities of their new 
guests. The age of technocracy has brought forth a situation in which the movement of people as well as their co-existence in different spheres of interaction now demands for a pedagogy of Humanities that should shed its adherence to tradition and open up for our shared existence. This move towards a cosmopolitan reading practice, which might even be a pedagogic counterpart to the ubiquitous flash mob existence of ours, might be the most pronounced legacy of technocracy for Humanities.

\section{Note}

i The latter refers to Parayi petta panthirukulam, a Kerala folktale which deals with the different castes, occupations and legends of Kerala.

\section{References}

Adelson, Leslie A. (2005). The Turkish Turn in Contemporary German Literature: Toward a New Critical Grammar of Migration. New York: Palgrave Macmillan.

Appadurai, Arjun. (1996). Modernity at Large: Cultural Dimensions of Globalization. Minneapolis: University of Minnesota Press.

Bennett, Jane. (2010). Vibrant Matter: A Political Ecology of Things, Durham, NC: Duke University Press.

Bhabha, H. (1984). Of Mimicry and Man: The Ambivalence of Colonial Discourse. October 28, 125.

Boes, Tobias (2012): Formative Fictions: Nationalism, Cosmopolitanism, and the Bildungsroman, Ithaca, New York: Cornell University Press and Cornell University Library.

Certeau, Michel de. (1984). Walking in the City. In The Practice of Everyday Life. Berkeley \& Los Angeles: University of California Press. 91-110

Derrida, Jacques. (2000). Of Hospitality. Stanford, California: Stanford University Press.

Deshpande, Satish.(1995) Communalising the Nation-Space: Notes on Spatial Strategies of Hindutva. Economic and Political Weekly, Vol.30, No.5o, Dec.16, 1995. pp.3220-3227

Herder, Johann Gottfried. (2008). Shakespeare. Princeton: Princeton University Press.

Huat, Chua Beng. (2016). Upswings in Liberal Education in Singapore. Conference presentation. Human Sciences and the Future of the University. Centre for Comparative Literature, University of Hyderabad. Nov.28.

Kasparov, Garry. (2017). Deep Thinking: Where Machine Intelligence Ends and Human Creativity Begins. Hachette India.

Levinas, Emmanuel. (1969). Totality and Infinity. Pittsburg, PA: Duquesne University Press.

Menon, Nivedita and Aditya Nigam. (2007). Power and Contestaion: India since 1989. Hyderabad: Orient Longman.

Prasad, M. (2014). The struggle to represent and sartorial modernity: on a visual dimension of Indian nationalist politics. Inter-Asia Cultural Studies, 15 (4), 572-88.

Prasad, M. (1996). Cultural Studies: A Speculative Montage. Seminar special issue on Cultural Studies. 
Ramanujan, A K. (1991). Three Hundred Ramayanas: Five Examples and Three Thoughts on Translation. In Paula Richman (ed.) Many Rāmāyaṇas: The Diversity of a Narrative Tradition in South Asia (pp. 2248). Berkley \& Los Angeles: University of California Press.

Sarukkai, S. (2017). Location of the Humanities. Comparative Studies of South Asia, Africa and the Middle East, 37 (1), 151-161.

Shapiro, Eve. (2015). Gender Circuits: Bodies and Identities in a Technological Age. New York and London: Routledge.

Spivak, Gayatri Chakravorty. (2012) Rethinking Comparativism. In An Aesthetic Education in the Era of Globalization. Massachusetts: Harvard University Press.

Tharu, S. (2016). The Promise and the Lie of the University. Tehelka, February 9.

Tharu, Susie, et al. (2007). Reservations and the Return to Politics. Economic and Political Weekly, Vol.42, No.49, December 8-14, pp.39-45

Viswanathan, Gauri. (1989). Masks of Conquest: Literary Study and British Rule in India. New York: Columbia University Press.

Wood, Andrew F. and Mathew J. Smith. (2005). Online Communication: Linking Technology, Identity, and Culture. New Jersey and London: Lawrence Erlbaum Associates, Publishers.

Mohamed Shafeeq Karinkurayil is a Post Doctoral Fellow at the Manipal Centre for Philosophy and Humanities where he currently teaches Literatures of Migration and Introduction to Film Studies. He was awarded $\mathrm{PhD}$ in Cultural Studies from the English and Foreign Languages University (EFLU), Hyderabad for his dissertation "A Worldly Home: Minor Cosmopolitanism and the Question of Identity, Malabar, 1947-77". Earlier he has taught in the Centre for Comparative Literature at the University of Hyderabad, and at the Department of Comparative Literature at the Central University of Kerala. His research interests are in popular and minority cultures in the postcolony. Orcid Id: oooo-0oo2-8163-0594. 